\title{
Genotyping of Acanthamoeba spp. Isolated from the Caspian Sea in Iran ${ }^{\dagger}$
}

\author{
Mahmoudi M.R. ${ }^{1,2, *}$ and Karanis P. ${ }^{3,4, *}$ \\ 1 Cellular and Molecular Research Center, Faculty of Medicine, Guilan University of Medical Sciences, \\ P.O. Box 3363., Rasht, Iran \\ 2 Medical Biotechnology Research Center, Guilan University of Medical Sciences, P.O. Box 3363., Rasht, Iran \\ 3 Medical Faculty and University Hospital, The University of Cologne, P.O. Box 50931., Cologne, Germany \\ 4 Department of Basic and Clinical Sciences, Medical School, Anatomy Centre, University of Nicosia, \\ P.O. Box., 24005 Nicosia, Cyprus \\ * Correspondence: mrmahmoodi2002@yahoo.com (M.M.R.); karanis.p@unic.ac.cy (K.P.); \\ Tel.: +98-13-33690921 or +98-13-33690884 (ext. 231) (M.M.R.); +357-22471813 (K.P.) \\ + Presented at the 4th EWaS International Conference: Valuing the Water, Carbon, Ecological Footprints of \\ Human Activities, Online, 24-27 June 2020.
}

Published: 9 August 2020

\begin{abstract}
Acanthamoeba spp. are widely distributed in the environment and have been reported to be causative agents of lethal encephalitis and keratitis. In this study, thirty water samples from the Caspian Sea were collected during 2018. Water samples were filtrated and the filtrate used for culture. The positive samples were subjected to Polymerase Chain Reaction (PCR) and nucleotide sequencing. Free-living amoebae were identified in 50\% (15/30) of the seawater samples. DNA sequencing revealed the presence of $\mathrm{T} 2$ and $\mathrm{T} 4$ genotypes. The results of the present study confirmed the presence of potentially pathogenic strains in seawater in this area. This awareness should be raised among environmental and public health professionals.
\end{abstract}

Keywords: Acanthamoeba; seawater; prevalence; Caspian Sea; Iran

\section{Introduction}

Acanthamoeba, a free-living amoeba, can be present in different environmental sources, including air, soil, dust, drinking water, seawater, and recreational water [1-3]. Acanthamoeba is the causative agent of granulomatous amoebic encephalitis (GAE) and amoebic keratitis (AK). AK mostly reported in persons after swimming while wearing contact lenses or inadequate contact lens care [4]. Acanthamoeba could harbor some pathogenic organisms such as Helicobacter, Pseudomonas, and Legionella [5].

The presence of Acanthamoeba was investigated in many water samples, which are frequently exposed to humans [4,6]. Tourists frequently visit the coastal area of the Caspian Sea in Guilan province, especially during the summer. Even though Acanthamoeba was investigated in some surface water in Guilan province [7-9], there is still a lack of knowledge about the prevalence and pathogenicity of Acanthamoeba in seawater in this area.

Exposure to Acanthamoeba occurs frequently through water contact and knowledge of the presence of the organisms in water sources is important in understanding transmission dynamics.

In the present study, the distribution Acanthamoeba was investigated in water samples collected from the coastal area of Caspian Sea in various cities in Guilan. 


\section{Material and Methods}

\subsection{Sampling Area}

This study was carried out in Guilan Province, in Northern Iran, May-June 2018. Guilan province $\left(37.2809^{\circ} \mathrm{N}, 49.5924^{\circ} \mathrm{E}\right)$ lies along the Caspian Sea. It has a humid subtropical climate with, by a large margin, the heaviest rainfall in Iran, reaching as high as 1900 millimeters (75 in) in the southwestern coast and generally, around 1400 millimeters (55 in).

In total, 30 samples were collected from the Caspian Sea in various cities of Guilan. Water samples were collected randomly from the Caspian Sea, including, Chamkhaleh, Kiyahshahr, and Bandaranzali.

These water sources were near residential areas or in public places. Water samples were taken $\sim 30$ to $60 \mathrm{~cm}$ from the shore and $\sim 10$ to $20 \mathrm{~cm}$ in depth. At least a volume of $500 \mathrm{~mL}$ for each water sample was collected in each place at 1-2 month intervals.

\subsection{Filtration and Culture Method}

About $500 \mathrm{~mL}$ of each sample were filtered through a cellulose nitrate filter (Millipore Corporation, Bedford, Madison, WI, USA), pore size $0.45 \mu \mathrm{m}$, using a vacuum pump. Then, the filters were inverted onto $1.5 \%$ non-nutrient agar plates coated with heat-killed Escherichia coli. The plates were incubated at $37{ }^{\circ} \mathrm{C}$ and the presence of cysts and trophozoites were controlled daily for 14 days using an inverted microscope. Microscopy detection was performed according to the Pussard and Pons criteria [10]. In addition, the pathogenicity of each isolate as a human pathogen was evaluated using a thermo-tolerance test by culturing in $42{ }^{\circ} \mathrm{C}$.

\subsection{DNA Extraction}

Material from positive plates was gently scraped and washed with PBS (pH 7.4) and centrifuge at $2000 \mathrm{rpm}$ for $5 \mathrm{~min}$. Finally, DNA was extracted using the tissue DNA extraction kit according to the manufacturer's instructions with some modifications. Briefly, the suspension including amoeba cysts or trophozoites were passed 10 times of freeze and thaw at $-196^{\circ} \mathrm{C}$ for $5 \mathrm{~min}$, followed by 5 min in boiling water.

\subsection{PCR Assay}

PCR was performed using JDP primer; (JDP1: 5'-GGCCCAGATCGTTTACCGTGAA-3') and JDP2: 5'-TCTCACAAGCTGCTAGGGGAGTCA-3') were used for the amplification of approximately $500 \mathrm{bp}$ of the $18 \mathrm{~S}$ rDNA gene called Diagnostic Fragment 3 (DF3) [11,12].

Thermal cycling conditions were $94{ }^{\circ} \mathrm{C}$ for $3 \mathrm{~min} ; 35$ cycles of $94{ }^{\circ} \mathrm{C}$ for $35 \mathrm{~s}, 56^{\circ} \mathrm{C}$ for $45 \mathrm{~s}, 72{ }^{\circ} \mathrm{C}$ for $45 \mathrm{~s}$; followed by a final extension at $72{ }^{\circ} \mathrm{C}$ for $5 \mathrm{~min}$. Acanthamoeba strains previously identified at our laboratory were used as a positive control and DNA-free water was used as a negative control.

The PCR products electrophoresis was done on $1.5 \%$ gel agarose stained with ethidium bromide solution and visualized under UV light.

\subsection{Nucleotide Sequencing}

For genotype identification, partial 18S rRNA sequencing (DF3 region) was performed with amplification primers. Sequencing results were compared with reference species for each genotype.

\section{Results}

In the present study, free-living amoebae were detected in 50\% (15/30) samples by culture in NNA media at room temperature. Ten samples were sequenced and five sequenced results give good quality and revealed the presence of T4 (1 sample) and T2 (4 samples) genotype (Table 1$)$. The pathogenic potential using the thermo-tolerance test was shown by $10 \%$ of the Acanthamoeba strains isolated from seawater. 
Potentially pathogenic Acanthamoeba was detected in all three sampling sites. Frequency of Acanthamoeba in water samples collected from seawater was $60 \%, 40 \%$, and $50 \%$ in Chamkhale, Kiyashahr, and Bandar Anjali, respectively.

Table 1. Frequency of Acanthamoeba spp. in water samples collected from the Caspian Sea in Guilan, Iran.

\begin{tabular}{cccc}
\hline Sampling Site & Number of Samples & Culture Result & Sequencing Results \\
\hline Chamkhaleh & 10 & 6 & T4 \\
Kiyahshahr & 10 & 4 & T2 \\
Bandaranzali & 10 & 5 & T2 \\
Total & 30 & 15 & \\
\hline
\end{tabular}

\section{Discussion}

In the present study, free-living amoebae were detected in 50\% samples by culture in NNA media.

In a study of seawater in Jamaica, West Indies, Acanthamoeba was identified in $49.6 \%$ of the seawater samples. The pathogenic potential was shown by $40.4 \%$ of the seawater strains according to the morphologies of the cysts and trophozoites, and thermo-tolerance and osmo-tolerance assays [6]. In the study of Gregory (2004), Acanthamoeba strains were isolated from beach sand $(\mathrm{n}=20)$ and nearly all beach isolates were genotype T4 [13]. In our present study, one sample belonged to the T4 genotype and T2 (four samples) genotype.

This is in concordance with the study of Maghsood et al., (2005), who reported Acanthamoeba T2 strains as the predominant genotype in water sources of Iran [14]. In opposition to our study, Mahmoudi et al., (2005) reported the T4 genotype as the most isolated strain in surface water in Guilan province [9]. The T4 genotype is the main cause of Acanthamoeba-related infection in Iran and worldwide $[4,5,14]$. The T2 genotype, which is scarcely reported in patients worldwide, was also identified in the present study.

In Guilan, some reports address free-living amoeba (FLA) isolation from surface water in the previous study [7-9]. However, there is a lack of knowledge about the prevalence and pathogenicity of Acanthamoeba in seawater in this area. Interestingly, in the present study, Acanthamoeba was isolated from coastal water with high salinity. Previous research revealed that Acanthamoeba strains which withstand extremes of osmolarities such as high salinity are more likely to be a pathogen of human and animals [15]. Moreover, the fact that Acanthamoeba spp. can act as natural vectors for pathogenic microorganisms has an impact on the public health [16]. Guilan receives millions of tourists annually; all water sources included in the present study were associated with human activity, mainly swimming. Therefore, for preventing contamination, it is necessary for public health authorities to inform the population and high-risk people, including contact lens wearers and immuno-compromised patients.

\section{Conclusions}

The existence of pathogenic Acanthamoeba spp. in the coasts of Guilan province has been confirmed. Guilan receives millions of tourists annually and all water sources included in the present study were associated with human activity, mainly swimming. It is necessary to inform the population and the high-risk people, including contact lens wearers and immuno-compromised patients.

Author Contributions: M.M.R.: Acquisition of data, technical and material support M.M.R. and K.P.: Analysis and interpretation of data, drafting of the manuscript and critical revision of the manuscript for important intellectual content. All authors have read and agree to the published version of the manuscript.

Funding: This work supported by Guilan University of Medical Sciences, Rasht, Iran. Ethical approval was received from the Ethics Committee of Guilan University of Medical Sciences (IR.GUMS.REC.1397.079). 
Conflicts of Interest: The authors declare that there is no conflict of interest.

\section{References}

1. Gornik, K.; Kuzna-Grygiel, W. Presence of virulent strains of amphizoic amoebae in swimming pools of the city of Szczecin. Ann. Agric. Environ. Med. 2004, 11, 233-236.

2. Tanveer, T.; Hameed, A.; Gul, A.; Martin, A. Quick survey for detection, identification and characterization of Acanthamoeba genotypes from some selected soil and water samples across Pakistan. Ann. Agric. Environ. Med. 2015, 22, 227-230.

3. Tanveer, T.; Hameed, A.; Muazzam, A.G.; Jung, S.Y.; Gul, A.; Matin, A. Isolation and molecular characterization of potentially pathogenic Acanthamoeba genotypes from diverse water resources including household drinking water from Khyber Pakhtunkhwa. Pakistan. Parasitol. Res. 2013, 112, 2925-2932.

4. Lorenzo-Morales, J.; Lindo, J.F.; Martinez, E.; Calder, D.; Figueruelo, E.; Valladares, B.; Ortega-Rivas, A. pathogenic Acanthamoeba strains from water sources in Jamaica, West Indies. Ann. Trop. Med. Parasitol. 2005, 99, 751-758.

5. Balczun, C.; Scheid, P.L. Free-living amoebae as hosts for and vectors of intracellular microorganisms with public health significance. Virus. 2017, 9, 65.

6. Ettinger, M.; Webb, S.; Harris, S.; McIninch, S.; Garman, G.; Brown, B. Distribution of free-living amoebae in James River, Virginia, USA. Parasitol. Res. 2003, 89, 6-15.

7. Mahmoudi, M.R.; Taghipour, N.; Eftekhar, M.; Haghighi, A.; Karanis, P.K. Isolation of Acanthamoeba species in surface waters of Gilan province-north of Iran. Parasitol. Res. 2012, 110, 473-477.

8. Mahmoudi, M.R.; Kazemi, B.; Haghighi, A.; Karanis, P. Detection of Acanthamoeba and Toxoplasma in river water samples by molecular methods in Iran. Iran. J. Parasitol. 2015, 10, 250-257.

9. Mahmoudi, M.R.; Rahmati, B.; Seyedpour, S.H.; Karanis, P. Occurrence and molecular characterization of free-living amoeba species (Acanthamoeba, Hartmannella and Saccamoeba limax) in various surface water resources of Iran. Parasitol. Res. 2015, 114, 4669-4674.

10. Pussard, M.; Pons, R. Morphologie de la paroi kystiqueet taxonomie du genre Acanthamoeba (Protozoa, Amoebida). Protistol 1977, 8, 557-598.

11. Schroeder, J.M.; Booton, G.C.; Hay, J.; Niszl, I.A.; Seal, D.V.; Markus, M.B.; Fuerst, P.A.; Byers, T.J. Use of subgenic $18 \mathrm{~S}$ ribosomal DNAPCR and sequencing for genus and genotype identification of Acanthamoeba from humans with keratitis and from sewagesludge. J. Clin. Microbiol. 2001, 39, 1903-1911.

12. Edagawa, A.; Kimura, A.; Kawabuchi-Kurata, T.; Kusuhara, Y.; Karanis, P. Isolation and genotyping of potentially pathogenic Acanthamoeba and Naegleria species from tap-water sources in Osaka, Japan. Parasitol. Res. 2009, 105, 1109-1117.

13. Booton, G.C.; Rogerson, A.; Davidian, T.; Seal, D.; Kelly, D.; Beattie, T.; Tomlinson, A.; Lares, F.; Fuerst, P.; Byers, T. Molecular and physiological evaluation of subtropical environmental isolates of Acanthamoeba spp., causal agent of Acanthamoeba keratitis. J. Clin. Microb. 2004, 51, 192-200.

14. Maghsood, A.H.; Sissons, J.; Rezaeian, M.; Nolder, D.; Warhurst, D.; Khan, N.A. Acanthamoeba genotype T4 from the UK and Iran and isolation of the T2 genotype from clinical isolates. J. Med. Microbiol. 2005, 54, 755-759.

15. Khan, N.A. Acanthamoeba, Biology and Pathogenesis, 1st ed.; Caister Academic Press: Norfolk, UK, 2009.

16. Mahmoudi, M.R.; Berenji, F.; Fata, A.; Najafzadeh, M.J.; Asadian, A.; Salehi, M. Morphological characterization of potentially pathogenic thermophilic amoebae isolated from surface water in Mashhad, Iran. Jundishapur J. Microbiol. 2015, 8, e25944, doi:10.5812/jjm.8(4)2015.25944.

(C) 2020 by the authors. Licensee MDPI, Basel, Switzerland. This article is an open access article distributed under the terms and conditions of the Creative Commons Attribution (CC BY) license (http://creativecommons.org/licenses/by/4.0/). 